\title{
Anette Grünewald
}

\section{Reform der Tötungsdelikte}

\section{Plädoyer für ein Privilegierungskonzept}

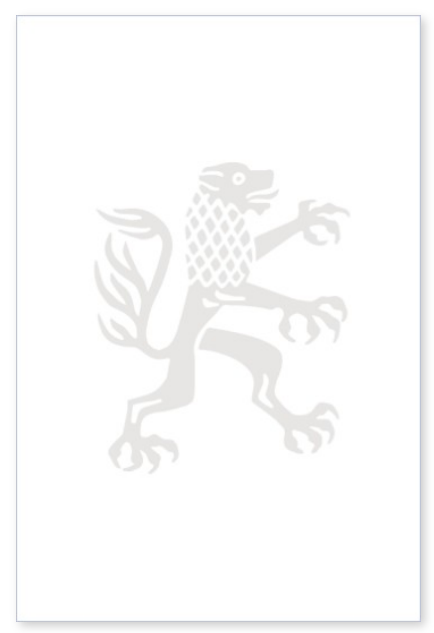

2016. VIII, 80 Seiten.

ISBN 978-3-16-154697-6

DOI 10.1628/978-3-16-154697-6

eBook PDF $14,00 €$

ISBN 978-3-16-154443-9

fadengeheftete Broschur 14,00€
Über die Reformbedürftigkeit der Tötungsdelikte, insbesondere des Mordparagrafen, besteht in der Strafrechtswissenschaft seit Jahrzehnten ein Konsens. Desgleichen besteht Einigkeit darüber, dass die in § 211 StGB absolut angeordnete lebenslang Freiheitsstrafe in vielen Fällen keine adäquate Sanktion darstellt. Darüber hinaus gehen die Auffassungen aber auseinander. Anette Grünewald zeigt, weshalb sich Mord als eine Erschwerungsnorm, sei es als Qualifikationstatbestand oder in Form von Regelbeispielen, nicht überzeugend begründen lässt, und plädiert für ein Privilegierungsmodell. Danach ist Mord die einfache vorsätzliche Tötung und damit zugleich der Grundtatbestand, während der Totschlag eine Privilegierung darstellt.

Anette Grünewald Studium der Rechtswissenschaft und der Philosophie in Freiburg i. Br. und in Hamburg; 1999 Promotion 2009 Habilitation; anschließend Lehrstuhlvertretungen; seit 2013 Inhaberin eines Lehrstuhls für Strafrecht und Strafprozessrecht an der Humboldt-Universität zu Berlin.

Jetzt bestellen:

https://mohrsiebeck.com/buch/reform-der-toetungsdelikte-9783161546976?no_cache=1

order@mohrsiebeck.com

Telefon: +49 (0)7071-923-17

Telefax: $+49(0) 7071-51104$ 